\title{
MORFOlogia E AVALIAÇÃo do CRESCIMENTO INICIAL DE PLÂNTULAS DE Bactris gasipaes Kunth. (ARECACEAE) EM DIFERENTES SUBSTRATOS ${ }^{1}$
}

\author{
VANESSA LORENCINI DA SILVA², FABÍOLA VITTI MÔRO³, CARLOS FERREIRA DAMIÃO FILHO ${ }^{3}$, JOSÉ \\ ROBERTO MÔRO ${ }^{3}$, BRENO MARQUES DA SILVA E SILVA ${ }^{4}$, HAMILTON CÉSAR DE OLIVEIRA CHARLO²
}

\begin{abstract}
RESUMO - Este trabalho teve por objetivos descrever a morfologia dos diásporos, as fases da germinação e determinar o substrato mais adequado para o crescimento inicial de plântulas de pupunha. Periodicamente, unidades representativas de cada fase de germinação foram retiradas para a descrição da sequiência dos eventos morfológicos. Os substratos usados para o crescimento inicial foram Plantmax HT, areia, terra (latossolo roxo) e outro com proporções iguais de terra, areia e esterco (TAE). Avaliou-se o crescimento inicial das plântulas aos 101 dias após o transplante, com base na sua altura, número de folhas, comprimento e largura das folhas. Observou-se que as sementes são albuminosas, com endosperma oleaginoso e de consistência relativamente dura. O embrião é lateral, periférico e relativamente indiferenciado, de forma cônica. A germinação inicia-se com o desenvolvimento de uma massa de células indiferenciadas na depressão micropilar. Posteriormente, esta massa de células torna-se cilíndrica, com a diferenciação dos primórdios caulinar e radicular. O primórdio caulinar é constituído por três bainhas envolvendo a primeira folha. Estas se abrem sucessivamente, permitindo a emergência da folha primária. Entre os substratos testados, de acordo com os parâmetros avaliados, os mais adequados para crescimento inicial de mudas de Bactris gasipaes Kunth foram o TAE e o Plantmax.
\end{abstract}

Termos para indexação: Bactris, pupunha, plântula, substrato, nutrientes.

\section{MORPHOLOGY AND EVALUATION OF INICIAL GROWTH OF Bactris gasipaes Kunth. SEEDLINGS IN DIFFERENT SUBSTRATA}

\begin{abstract}
This work aimed to describe the morphology of the diaspore, the phases of germination and to determine the most adequate substratum for germination and development of peach palm. Periodically, representative units of each phase of germination had been removed for the description of the sequence of the morphological events. The used substrata for germination and initial growth were Plantmax HT, sand, rich soil and another one with equal ratios of soil, sand and manure (SSM). It was evaluated the percentage and the speed of germination and the initial growth of the seedlings at 101 days after the sowing, on the basis of their leaf height, leaf number, length and width of the leaves. It was observed that the seeds are albuminous, with an oleaginous and hard endosperm. The embryo is lateral, peripheral and relatively undifferentiated, with conic shape. The germination starts with an undifferentiated mass of cells at the micropilar depression. Afterward that structure becomes cylindrical, with the differentiation of the shoot and the primordial roots. The shoot is constituted by three sheathings wrapping the primary leaf. They open themselves successively allowing the primary leaf to emerge. Among the substrata the more adequate ones for the initial grow of Bactris gasipaes seedlings were SSM and Plantmax.
\end{abstract}

Keywords: Bactris, peach palm, seedlings, substratum, nutrients.

\section{INTRODUÇÃO}

Bactris gasipaes Kunth, popularmente conhecida como pupunha ou pupunheira, é uma palmeira multicaule de até $20 \mathrm{~m}$ de altura e 15 a $25 \mathrm{~cm}$ de diâmetro, com acúleos marrons ou cinzas ou acúleos ausentes (Lorenzi et al., 1996).

A sua madeira é utilizada para construções, móveis, tacos e artesanato, mas a sua maior utilização é como produtora de frutos e palmito, fazendo parte da dieta da população amazônica (Mora-Urpí, 1983; Aguiar et al., 1980; Lorenzi et al., 1996). A pupunheira possui diversas formas de uso na agroeconomia moderna dos trópicos úmidos: o fruto para consumo humano direto, farinha para panificação, óleo vegetal, ração animal e o palmito (Clement \& MoraUrpí, 1987).

Inicialmente, a pupunheira foi domesticada pelos primeiros povos da Amazônia por seus frutos abundantes, ricos em energia e $\beta$-caroteno, e em muitas partes da Amazônia ocidental tornou-se importante componente de segurança alimentar na economia e subsistência (Aguiar et al., 1980; Yuyama et al., 1999; Clement, 2003). Nos últimos anos, o cultivo da pupunheira para a produção de palmito vem despertando o interesse de agricultores de todo o País. Esse interesse é devido, principalmente, à busca de novas opções de cultivo em substituição aos tradicionais, em virtude dos baixos preços alcançados por esses últimos no mercado (Bovi, 1997; Môro 2003). Ademais, as vantagens da pupunha sobre as tradicionais espécies produtoras de palmito (Euterpe edulis Mart. e E. oleracea Mart.) são a sua precocidade (1,5 a 2 anos para o primeiro corte), capacidade de formar perfilhos, baixos níveis de compostos fenólicos e fibras, quantidades substanciais de amido, óleo e vitamina A (Chaves et al., 1984; Fernandes et al., 1990; Bovi, 1997).

Pinheiro \& Araújo-Neto (1987) defendem que estudos descritivos da germinação de sementes de palmeiras são importantes para o conhecimento completo do processo germinativo e básico para o desenvolvimento técnico eficiente de produção de mudas. As medidas vegetativas de altura, número de folhas e número de perfilhos, associadas às outras medidas produtivas, são consideradas como essenciais para comparar resultados e estimar vários parâmetros fisiológicos de crescimento e produção (Clement $\&$ Bovi, 2000). De acordo com Nishikawa (1995), o diâmetro da planta, o número de folhas, a altura de plantas e a área foliar são altamente correlacionadas entre si com a produção de palmito, já na fase juvenil da planta.

\footnotetext{
1 (Trabalho 025-2006). Recebido: 13-03-2006. Aceito para publicação: 25-08-2006.

${ }^{2}$ Graduando(a) em Agronomia - Universidade Estadual Paulista (UNESP) / Faculdade de Ciências Agrárias e Veterinárias Câmpus Jaboticabal (FCAV) / Departamento de Biologia Aplicada à Agropecuária (DBAA). E-mail: vanlorencini@yahoo.com.br ; hamiltoncharlo@ yahoo.com.br

${ }^{3} \operatorname{Prof}^{(\mathrm{a})}$. Dr(a). - UNESP/FCAV/DBAA. Via de Acesso Prof. Dr. Paulo Donato Castellane, s/n. CEP 14884-900, Jaboticabal - SP. E-mail: fabiola@ @ fcav.unesp.br; damião@fcav.unesp.br; jrmoro@fcav.unesp.br; sbianco@fcav.unesp.br

${ }^{4}$ Bolsista de Mestrado do CNPq - Mestrando em Agronomia [Produção e Tecnologia de Sementes]UNESP/FCAV - Departamento de Produção Vegetal. Email: silvabms@fcav.unesp.br
} 
As pesquisas sobre palmeiras são importantes para subsidiar o desenvolvimento e a expansão de técnicas para sua domesticação, seleção, cultivo e manejo, favorecendo, assim, o aumento da produtividade e, por conseguinte, o desenvolvimento de novas formas de aproveitamento e comercialização de produtos e subprodutos desse material (Jardim \& Cunha, 1998). Desta forma, para proporcionar o aproveitamento do potencial econômico das palmeiras regionais, torna-se necessária a ampliação dos estudos básicos e aplicados para um melhor conhecimento de sua diversidade, ocupação no ecossistema, evolução, adaptação e desenvolvimento de métodos adequados para o manejo e utilização de seu potencial.

Assim, o objetivo do presente trabalho foi descrever morfologicamente o diásporo, o desenvolvimento pós-seminal e determinar o substrato mais adequado para o crescimento inicial de plântulas de pupunha.

\section{MATERIAL E MÉTODOS}

A seleção das matrizes, bem como a coleta dos frutos de Bactris gasipaes Kunth foram realizadas de acordo com recomendações gerais de Figliolia \& Aguiar (1993). Foram selecionadas 5 matrizes, localizadas no Viveiro Experimental da FCAV / UNESP - Jaboticabal (SP), das quais foram coletados os frutos. Posteriormente, a descrição e a análise das sementes foram realizadas no Laboratório de Morfologia Vegetal do DBAA-FCAV-UNESP.

O epicarpo e o mesocarpo dos frutos foram retirados por meio da fricção em peneira de malha de aço sob água corrente, obtendo-se os diásporos, constituídos pelas sementes envolvidas pelo endocarpo.

Para os estudos morfológicos, o diásporo foi cortado longitudinalmente, para observação e documentação de suas características internas, sendo esquematizados em estereomicroscópio com câmara clara.

Para descrever a sequiência dos eventos morfológicos da germinação, 50 diásporos foram semeados em bandejas plásticas contendo Sphagnum sp., mantidas em temperatura ambiente $\left(22,2^{\circ} \mathrm{C}\right.$ $\pm 5,2$ ). Periodicamente, foram retiradas unidades representativas de cada fase de germinação. Para as descrições morfológicas, foram usadas as terminologias empregadas por Tomlinson (1961) e Barroso et al. (1999).

Para avaliar o efeito dos substratos, diásporos germinados foram transferidos para sacos plásticos de $1 \mathrm{~L}$ contendo areia, terra (latossolo roxo), Plantmax Hortaliças (HT) ou uma mistura com proporções iguais de terra, areia e esterco (TAE), mantidos em casa de vegetação coberta com sombrite $50 \%$ e regados diariamente com água. Foram utilizadas 4 repetições de 25 diásporos por substrato, em delineamento inteiramente casualizado.

Aos 101 dias após a semeadura, foram realizadas mensurações de comprimento e largura de folhas, diâmetro do colo, número de folhas e altura de todas as plântulas de cada substrato. As comparações entre as médias analisadas foram feitas mediante a aplicação do teste de Tukey, ao nível de 5\% de probabilidade.

\section{RESULTADOS E DISCUSSÃO}

Os diásporos de pupunha possuem forma globosa a elipsóide, com endosperma homogêneo, oleaginoso, de consistência dura, ocupando quase todo o espaço interno da semente (Figura 1). Da mesma forma, os diásporos de Bactris gastoniana Barb. Rodr., B. humilis (Wallace) Burret. e B. simplicifrons Mart., de acordo com Henderson \& Scariot (1993), possuem endosperma homogêneo. Semelhantemente, Viana (2003) descreve o diásporo de Livistona rotundifolia (Lam.) Mart. como globoso e com a maior parte ocupada pelo endosperma rígido.
O embrião de pupunha é lateral, periférico e relativamente indiferenciado, de forma cônica, com uma das extremidades côncava, no interior da qual se encontra uma pequena protuberância, e a outra extremidade, arredondada e mais afilada (Figura 1). De forma semelhante, os embriões de Livistona rotundifolia (Lam.) Mart. e de outras espécies de Livistoninae são laterais, periféricos, cônicos e pouco diferenciados (Viana,2003; Alves,1986).

A germinação das sementes de pupunha inicia-se com o desenvolvimento de uma massa de células indiferenciadas na depressão micropilar, denominada botão germinativo (Figuras 1 e 2). Posteriormente, essa massa de células torna-se cilíndrica, com a diferenciação dos primórdios caulinares e radiculares, sendo o primeiro envolto por uma bainha fechada. Concomitantemente, ocorre o desenvolvimento de raízes adventícias no eixo embrionário (Figura 2).

De acordo com o conceito de Tomlinson (1960; 1961), a germinação da pupunha é do tipo adjacente ligulada, pois o cotilédone não apresenta grande alongamento, ocorrendo o desenvolvimento da plântula adjacente ao diásporo (Figura 2).

Para Livistona rotundifolia (Lam.) Mart, segundo Viana (2003), a plúmula é composta por duas folhas incompletas denominadas bainhas, que revestem a primeira folha juvenil completa, denominada de eófilo. Nesta fase, observa-se juntamente o aparecimento de raízes secundárias.

Nas plântulas de pupunha, o sistema radicular fasciculado é abundante, com raízes adventícias diferenciadas e várias raízes laterais, não sendo observados pêlos absorventes. De acordo com Tomlinson (1990), as palmeiras raramente apresentam um camada pilífera considerável.
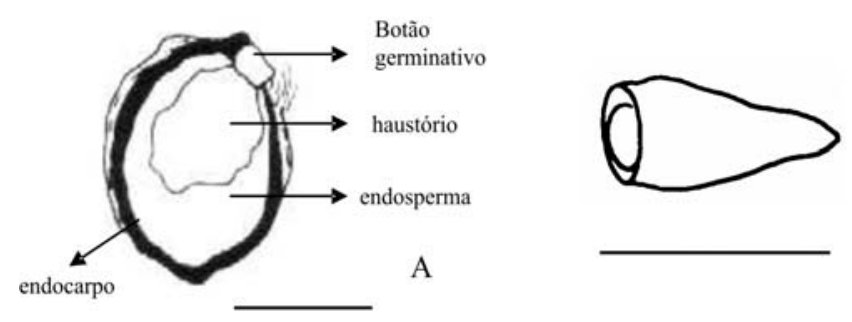

FIGURA 1 - A. Corte longitudinal do diásporo de Bactris gasipaes Kunth $($ barra $=1 \mathrm{~cm})$. B. Embrião (barra $=2 \mathrm{~mm})$.
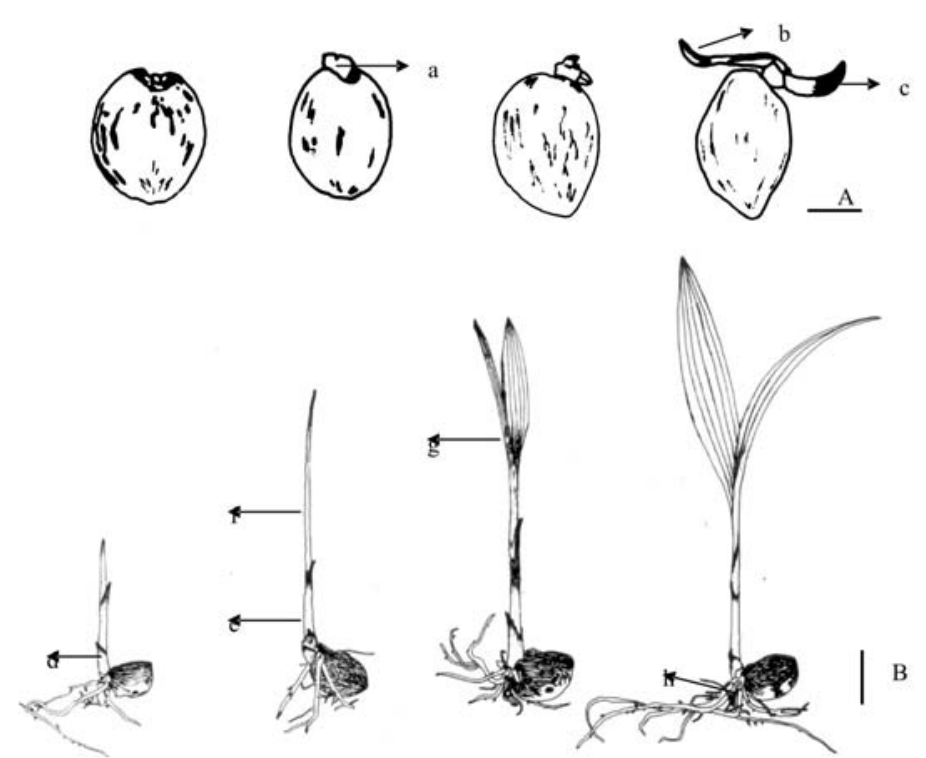

FIGURA 2 - Fases iniciais da germinação de sementes de Bactris gasipaes Kunth.em substrato Sphagnum sp. a) botão germinativo; b) primórdio radicular; c) primórdio caulinar; d) primeira bainha; e) segunda bainha; f) terceira bainha; g) folha primária; h) raízes adventícias. A. Barra $=1 \mathrm{~cm} ;$ B.Barra $=2 \mathrm{~cm}$. 
TABELA 1 - Médias de comprimento de folha (CF), largura de folha (LF), número de folhas (NF) e altura de plântulas (ALT) de pupunha aos 101 após o transplante.

\begin{tabular}{lcccc}
\hline Substrato* $^{*}$ & CF (cm) & LF (cm) & NF & ALT (cm) \\
\hline Plantmax & $9,78 \mathrm{ab}$ & $2,08 \mathrm{a}$ & $2,43 \mathrm{a}$ & $15,32 \mathrm{ab}$ \\
\hline Terra & $9,95 \mathrm{ab}$ & $1,87 \mathrm{a}$ & $2,33 \mathrm{a}$ & $13,93 \mathrm{ab}$ \\
\hline Areia & $8,90 \mathrm{~b}$ & $1,78 \mathrm{~b}$ & $2,47 \mathrm{a}$ & $13,38 \mathrm{~b}$ \\
\hline TAE & $11,30 \mathrm{a}$ & $2,67 \mathrm{a}$ & $2,23 \mathrm{a}$ & $16,79 \mathrm{a}$ \\
\hline CV\% & $\mathbf{2 9 , 0 6}$ & $\mathbf{3 6 , 6 0}$ & $\mathbf{2 7 , 9 8}$ & $\mathbf{3 0 , 7 6}$ \\
\hline
\end{tabular}

*Médias seguidas pela mesma letra na coluna não diferem entre si, pelo Teste de Tukey, a 5\% de probabilidade.

O primórdio caulinar é constituído por três bainhas envolvendo a primeira folha. Estas se abrem sucessivamente, permitindo a emergência da folha primária. A primeira bainha é localizada próxima ao eixo embrionário e apresenta pequena extensão quando comparada com as demais. Pode-se observar que a folha primária é bífida, com nervuras paralelas típicas (Figura 2).

De acordo com Viana (2003), as primeiras folhas de Livistona rontundifolia (Lam.) Mart. são lanceoladas e simples, com nervação paralela, compostas por nervuras largas, dispostas longitudinalmente. Enquanto Castro (1993) relata que plântulas de Euterpe precatoria Mart. possuem de dois a três folíolos, Khan \& Granville (1997) observaram que a morfologia foliar das palmeiras, geralmente, varia durante a ontogênese, ou seja, há plântulas que apresentam folhas inteiras, bífidas ou não, e quando adultas, as folhas são pinadas.

No interior do diásporo, ocorre o desenvolvimento de uma estrutura haustorial, que digere o endosperma, ocupando, gradualmente, todo o espaço interno da semente. O haustório possui textura porosa e é constituído de células parenquimáticas de paredes delgadas, com grandes espaços intercelulares e abundante conteúdo granular, provavelmente constituído de amido (Figura 3). O consumo das reservas nutritivas da semente de pupunha pelo haustório e a concomitante produção fotossintética pelo eófilo marcam o final da fase de plântula, de acordo com o conceito de Tomlinson (1990).

Desde o início do processo germinativo até a formação da plântula normal, o diásporo está firmemente ligado à plântula por meio do pecíolo cotiledonar (Figura 2). A mesma estrutura foi observada por Aguiar \& Mendonça (2003) em Euterpe precatoria Mart.

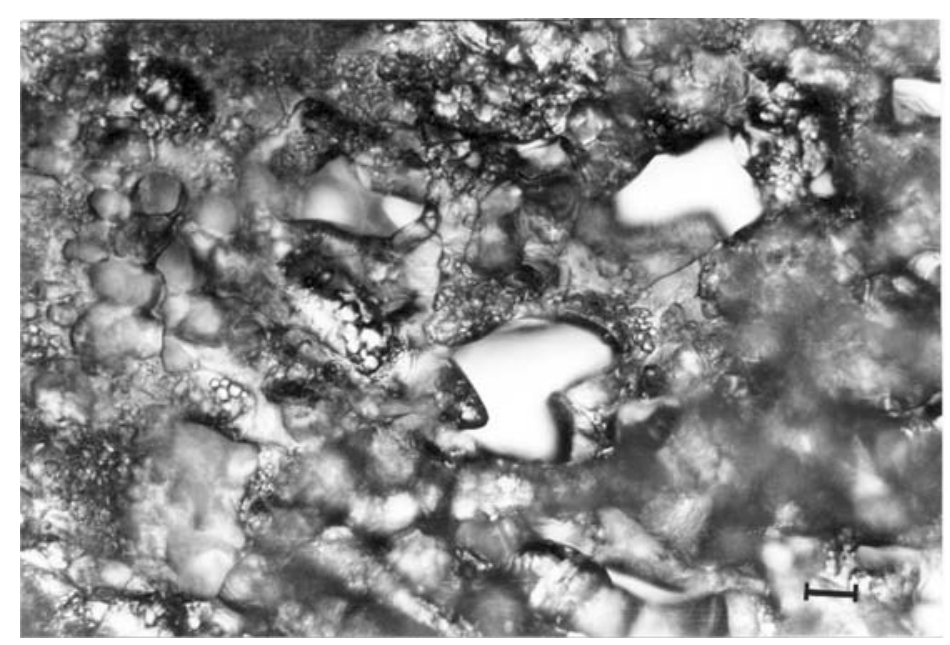

FIGURA 3 - Estrutura anatômica do tecido haustorial de semente de Bactris gasipaes Kunth. Barra $=50 \mu \mathrm{m}$.
O comprimento de folhas diferiu significativamente entre os substratos avaliados, aos 101 dias após a semeadura. Os maiores valores de comprimento e largura de folhas foram observados nos substratos TAE, terra e Plantmax, e os menores, no substrato areia, de acordo com dados da Tabela 1. Da mesma forma, os maiores valores de altura de plântulas foram obtidos em TAE, Plantmax e terra, e os menores valores, em areia (Tabela 1). Quanto ao número de folhas, aos 101 dias após o plantio, não houve diferenças significativas entre os substratos para essa característica (Tabela 1).

Cunha \& Jardim (1995) relatam que o comprimento da radícula e do caule de plântulas de três variedades de Euterpe oleracea Mart. não diferiram quando foram utilizados vermiculita e solo hidromórfico do tipo Glei Pouco Húmico, para emergência em casa de vegetação.

Iossi et al. (2003) observaram que plântulas de Phoenix roebelenii $\mathrm{O}^{\prime}$ Brien tinham menor desenvolvimento quando usados os substratos areia, vermiculita e serragem.

Lorenzi (1992) recomenda a utilização de um substrato organoargiloso para produção de mudas de pupunha, enquanto, para crescimento inicial de plântulas de Phoenix roebelenii O’Brien, Iossi et al. (2003) indicam o esfagno como substrato mais adequado quando comparado com serragem, areia e vermiculita, mesmo com porcentagens de germinação semelhantes aos dois últimos substratos citados.

\section{CONCLUSÃO}

A morfologia da unidade de dispersão, da germinação e do crescimento inicial de Euterpe edulis pode auxiliar estudos do ciclo biológico, da regeneração natural, do manejo e da conservação dessa espécie. Entre os substratos testados, de acordo com os parâmetros avaliados, os mais adequados para o crescimento inicial de plântulas de Bactris gasipaes Kunth são o TAE e o Plantmax.

\section{REFERÊNCIAS}

AGUIAR, M.O.; MENDONÇA, M.S. Morfoanatomia de semente de Euterpe precatoria Mart. (Palmae). Revista Brasileira de Sementes, Pelotas, v. 25, n. 1, p. 37-42, 2003.

AGUIAR, J.P.L.; MARINHO, H.A.; REBÊLO, Y.S.; SHRIMPTON, R. Aspectos nutritivos de alguns frutos da Amazônia. Acta Amazônica, Manaus, v. 10, n. 4, p. 755-758, 1980.

ALVES, M.R.P. Palmeiras: botânica, classificação e distribuição geográfica. 1986. Monografia (Trabalho de Graduação em Agronomia) - Faculdade de Ciências Agrárias e Veterinárias, Universidade Estadual Paulista, Jaboticabal, 1986. 
BARROSO, G.M.; MORIM, M.P.; PEIXOTO, A.L.; ICHASO, C.L.F. Frutos e Sementes: Morfologia aplicada à sistemática de dicotiledôneas. Viçosa-MG: Editora UFV. 1999. 443p.

BOVI, M.L.A. Expansão do cultivo da pupunheira para palmito no Brasil. Horticultura Brasileira, Brasília, v.15, p. 183-185, 1997. Suplemento

CASTRO, A. Extractive exploitation of the açai (Euterpe precatoria) near Manaus, Amazônia. In: TropicAl forests, people and flood: biocultural interactions and applications to development. Paris: UNESCO, 1993. v. 15, p.779-782.

CHAVES, J.M.; PECHINK, E.; MATTOSO, E.I.V. Pupunha (Guilielma speciosa Mart.); Estudo da constituição química e do valor alimentício. Revista de Química Industrial, Rio de Janeiro, v. 17, p. 186-187. 1984.

CLEMENT, C.R. A subutilização da pupunha: Lições de P\&D em palmeiras amazônicas. In: CONGRESSO NACIONAL DE BOTÂNICA, 54., 2003, Belém-PA. Anais... Belém: MPEG, UFRA; EMBRAPA, Brasil/Museu Paraense Emílio Goeldi, 2003.

CLEMENT, C.R.; BOVI, M.L.A. Padronização de medidas de crescimento e produção em experimento com pupunheiras para palmito. Acta Amazonica, Manaus, v.30, n.3, p. 349-362. 2000.

CLEMENT, C.R.; MORA-URPÍ, J. The pejibaye (Bactris gasipaes H.B.K., Arecaceae): multi-use potential for the lowland humid tropics. Journal of Economic Botany, Washington, v. 41, n.2, p. 302-311, 1987.

CUNHA, A.C.C.; JARDIM, M.A.G. Avaliação do potencial germitativo em açaí (Euterpe oleracea Mart.) variedades preto, branco e espada. Boletim do Museu Paraense Emílio Goeldi Série Botânica, Belém, v. 11, n. 1, p. 55-60. 1995.

FERNANDES, M.; BLANCO, A.; MORA-URPÍ, J. Definición de las características químico-nutricionales de cuatro problaciones de pejibaye (Bactris gasipaes H.B.K.). Boletim Informativo Universidade de Costa Rica, v. 2, n. 1, p. 6-9. 1990.

FIGLIOLIA, M.B; AGUIAR, I.B. 1993. Colheita de sementes. In: AGUIAR, I.B.; PIÑA-RODRIGUES, F.C.M.; FIGLIOLIA, M.B. (Ed.). Sementes florestais tropicais. São Paulo: ABRATES, 1993. p 275-302.

HENDERSON, A.; SCARIOT, A. Aflórula da reserva Ducke, I: Palmae (Arecaceae). Acta Amazônica, Manaus, v. 23, n. 4, p. 349-369. 1993.

IOSSI, E.; SADER, R.; PIVETTA, K.F.L. ; BARBOSA, J.C. Efeitos de substratos e temperaturas na germinação de sementes de Tamareira-Anã (Phoenix roebelenii O’Brien). Revista Brasileira de Sementes, Pelotas, v.25, n. 2, p. 63-69, 2003.
JARDIM, M. A. G.; CUNHA, A. C. C. Usos de Palmeiras em uma Comunidade Ribeirinha do Estuário Amazônico. Boletim do Museu Paraense Emílio Goeldi - Série Botânica, Belém, v. 14, n. 1, p. 69-76, 1998.

KAHN, F.; GRANVILLE, J. Palms in forest ecosystems of Amazonia. New York: Springer Verlag, 1997. 226p. (Ecological Study, 95).

LORENZI, H.; SOUZA,H.M.; MEDEIROS-COSTA, J.T.; CERQUEIRA. L.S.C.; VON BEHR, N. Palmeiras no Brasil: exóticas e nativas. Nova Odessa: Plantarum, 1996. 303 p.

MORA-URPÍ, J. El pejibaye (Bactris gasipaes H.B.K): origem, biologia floral y manejo agronômico: In: WORKSHOP ON UNDER UTILIZED PALMS TROPICALAMERICA, 43., 1983. Proceedings... p. 118-160.

MÔRO, J. R. A cultura da pupunha para a produção de palmito. Disponível em: <www.pupunha.com.br>. Acesso em: 2003.

NISHIKAWA, M. A. N. Avaliação de progênies de meios-irmãos de pupunha (Bactris gasipaes). 1995. Tese (Doutorado em Agronomia-Genética e Melhoramento de Plantas) - Faculdade de Ciências Agrárias e Veterinárias, Universidade Estadual Paulista, Jaboticabal, 1995.

PINHEIRO, C.U.B.; ARAÚJO-NETO, A. Descrição do processo germinativo de semente de babaçu (Orbignya phalerata Mart.). São Luís - Maranhão: EMAPA, 1987. 7 p. (Comunicado Técnico, 14).

TOMLINSON, P.B. Essays on the morphology of palms; germination and seedlings. Principes, Lawrence, v. 4, n. 2, p. 56-61, 1960.

TOMLINSON, P.B. Anatomy of the monocotyledons. In: TOMLISON, P.B. II Palmae. Oxford: C.R. Metcalf, 1961. p. 308311.

TOMLINSON, P.B. The structural biology of palms. Oxford, Clarendon Press. 460p. 1990,

VIANA, F.A.P. Estudos sobre germinação e morfoanatomia de diásporos e da plântula de Livistona rotundifolia (Lam.) Mart. (Arecaceae). 2003. Dissertação (Mestrado em Agronomia Produção e Tecnologia de Sementes) - Faculdade de Ciências Agrárias e Veterinárias, Universidade Estadual Paulista, Jaboticabal, 2003.

YUYAMA, L.K.O.; YONEKURA, L.; AGUIAR, J.P.L.; SOUSA, R.F.S. Biodisponibilidade de vitamina A da pupunha (Bactris gasipaes Kunth) em ratos. Acta Amazonica, Manaus, v. 29, n. 3, p. 497500. 1999. 